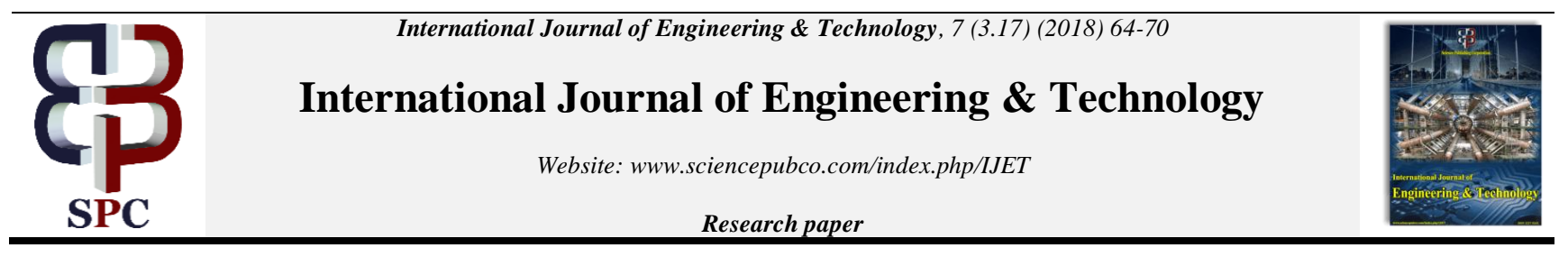

\title{
A Fault Diagnosis Expert System for Commercial Bus Manufacturing process
}

\author{
Chee Nian, $\operatorname{Tan}^{1,2^{*}}$ and Chee Fai, $\operatorname{Tan}^{1,2}$ \\ ${ }^{I}$ Innovation and Sustainability in Machine Technologies Research Group \\ Centre of Advanced Research on Energy \\ ${ }^{2}$ Faculty of Mechanical Engineering \\ Universiti Teknikal Malaysia Melaka \\ Hang Tuah Jaya,76100, Durian Tunggal, Melaka, Malaysia \\ *Corresponding author Email: jasontan0710@hotmail.com
}

\begin{abstract}
Bus manufacturing is one of the important assets in automotive industries as well as mode of public transportation. The design process is difficult and long throughout time. Moreover, there are many manuals, rules and regulation according to different standard which make the standardization and design process to be difficult and time consuming. Hence, this project describes the use of an expert sys tem shell for commercial bus design. In bus manufacturing field, design of commercial bus is heavily depending on human experts. With the help of expert system, process of design commercial bus will be shortened up to 56.5\% compared to conventional way. The developed system can be used as a training module for inexperienced personnel. In this research work, the fault diagnosis system was developed by using Kappa-PC expert system shell. It is supported by object orientated technology for the MS window environment. Lastly, the developed system will be validated with a case study to verify the capability of the developed system.
\end{abstract}

Keywords: Bus; Expert System; Fault Diagnosis

\section{Introduction}

The Malaysian commercial bus body and chassis is manufactured by local bus body manufacturer. The bus chassis from the company is a monocoque designed chassis. Manufacturer will face difficulties to get the knowledge from the expert when the expert is not around form working place. The expert for the bus body production process is engineer, technician, mechanic, contractor and supplier. Their production of equipment and machine are depending heavily on human expertise for production and it is costly. The knowledge and experience of the expert will be lost if he/she is resigned or retired. A system that is able to store the expert knowledge is needed in any industry with highly depending on experts. With the expert system, processes will be standardized and accuracy will be increased compared to the conventional way [1].

Based on the result above, this research highlights on knowledgebased system (KBS) in troubleshooting of bus body and chassis design process. The main objective of the research is to develop an expert fault diagnosis system framework for the commercial bus. Germignani and Dym concluded that knowledge based expert system is computer software that overcomes problems with expert solution [2,3]. With the present of expert system, time used in design stage regarding on calculation related to rules and regulation can be shorten and suitable recommendation will be given. In addition, expert system is one of the artificial intelligence (AI) technologies that were developed from research and it is able to simulate the human cognitive skills for problem solving.

Hence, an expert system called Kappa-PC Software is been used as a software system to provide a standardized methodological approach to solve important and complex problem normally done by human experts [4]. The system will generate friendly prompts according to the user data. Friendly prompts will be shown as an advice to the user on how to solve the current problems.

\section{Expert System}

Xian and Zeng [5] developed a fault diagnosis system for mechanical systems. The developed system able to diagnose the stability and mutability of the mechanical systems based on WPA signal. Deng et al [6] developed intelligent methods of human error in fault diagnosis, and managed to diagnose a new failure precisely and rapidly. Syiam [7] developed a neural expert system to diagnoses early eye diseases of patient. The developed system based on the patient signs and symptoms, and uses the multiplayer feed forward networks with a single hidden layer [8].

In addition, an expert system is a computer program that stores the specific experts' knowledge and experience to solve problems or giving advice. Jackson (1998), Catal et al. (2011), Lei et al. (2011) 
and Luo et al. (2012) concluded that expert system technology derives from Artificial Intelligence (AI) which defined as a branch of computer science concerned with the design and capable of imitating human intellectual skills [9-11].

Refer to Fig 1, an expert system is built by getting together a knowledge base, which is interpreted by an off-the-shelf program that contains an inference engine. A knowledge base comes with such a program, which is typically called as shell. The end user of the application will be interacting with the shell via the inference engine, which uses the knowledge put in the knowledge base to answer and solve problems [9].

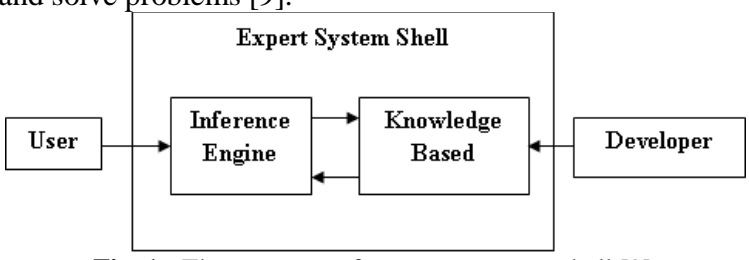

Fig. 1: The structure of an expert system shell [9]

Expert system is used to keep the institutional or corporate memory by saving the worker knowledge and experience. If the worker resigns or retires, the company still can retrieve their knowledge and experience. Liebowitz (1995) presented other important reasons for using expert systems are [12]:

- A useful "device" if expertise is unavailable or expensive;

- A helpful device under constraints of time, pressure and money;

- A way to replace training module;

- A vehicle for improving worker productivity, time and cost savings;

With the expert system, processes or tool that implemented will be standardized by comparing to the conventional way. Therefore, the quality of product that is produced will be finer and better. As a result from above, this project highlighted application on knowledge-based system (KBS) approached in trouble shooting of vehicle production process [13].

\section{Kappa-PC}

There are many expert system shell available in the market such as Exsys Developer, KEE, VP-Expert, KnowledgePro, etc. Kappa-PC is one of the expert shell and it is generates standard ANSI C code and GUI (Graphical User Interface) runtimes. KAPPA-PC can build mission-critical applications that form the core of business operations $[14,15]$.

Mansyur et al. (2013) and C.K et al. (2009) concluded KAPPA-PC is a rule-based expert system shell that helped in developing an expert system $[16,17]$. The main menu of developed KAPPA-PC system is shown in Fig 2. Fig 3 shows the goal editor in the developed system.

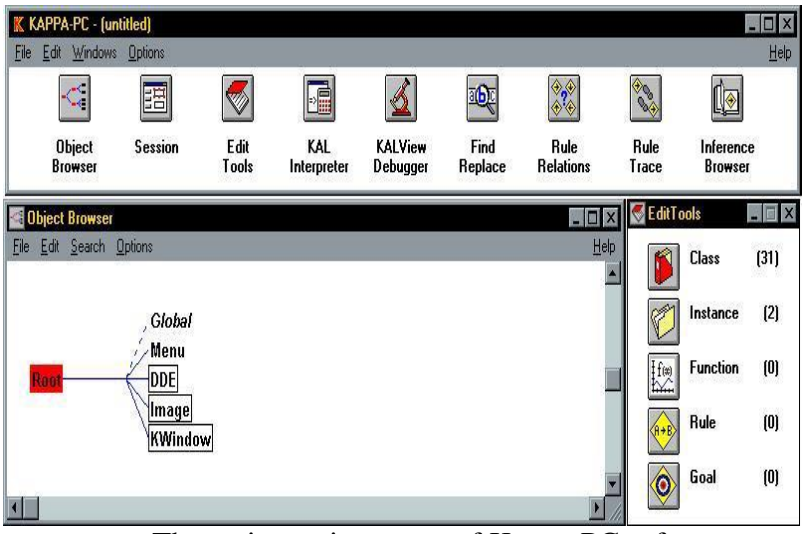

Fig. 2: The main session menu of Kappa-PC software

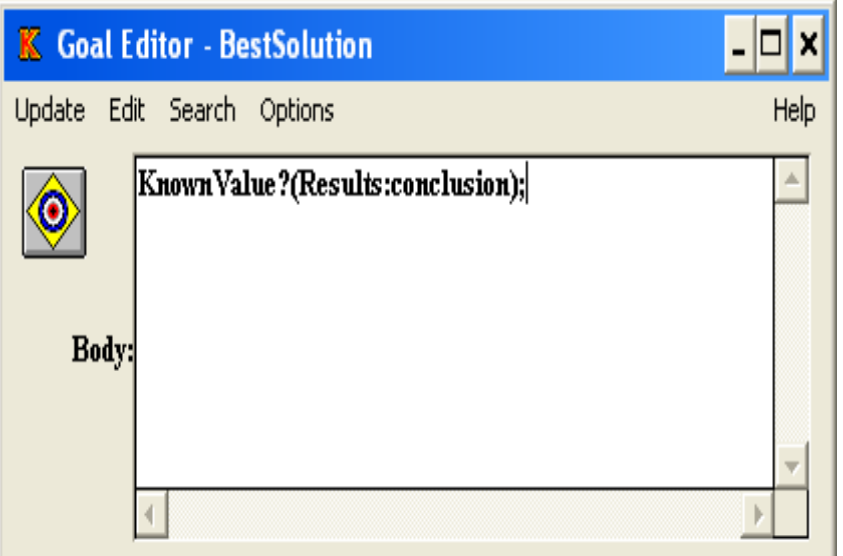

Fig. 3: The goal editor of Kappa-PC software

The tools in the main menu of Kappa-PC software is as shown in Table 1.

Table 1: Tools and function in Kappa-PC software

\begin{tabular}{|c|c|}
\hline Tools & Function \\
\hline Object Browser & Object can be created and edited in this function. \\
\hline Session & $\begin{array}{l}\text { In this function, session window can create or edit a } \\
\text { graphical resource editor which will forming a user- } \\
\text { interface in the expert system }\end{array}$ \\
\hline Edit Tools & $\begin{array}{l}\text { This function including invoking the editors of } \\
\text { classes, instances, function, rules and goals. }\end{array}$ \\
\hline $\begin{array}{l}\text { KALView } \\
\text { Debugger }\end{array}$ & This is a tool use for debugging KAL code. \\
\hline Find/Replace & $\begin{array}{l}\text { This is use for searching and replacing text in the } \\
\text { knowledge base }\end{array}$ \\
\hline Rule Relations & $\begin{array}{l}\text { This shows the relationships of the graphical tool and } \\
\text { the rules created in the knowledge base. }\end{array}$ \\
\hline $\begin{array}{l}\text { Rule Trace and } \\
\text { Inference Browser }\end{array}$ & $\begin{array}{l}\text { The display of graphical traces of the rules and you } \\
\text { can step in the inference process. }\end{array}$ \\
\hline
\end{tabular}

User interface shown at Fig 4 is one of the developed friendly session system. Fig 5 shows the developed framework for the expert system. It comprises of three main parts which is the knowledge acquisition module, knowledge based and the expert system shell. The inference engine is an important part of an expert system which works based on rules. The inference engine scans and checks the condition given in the rules depending on the chaining process defined in the reasoning. The reasoning process is classified into two namely backward or forward chaining. Rules are scanned until one is found when constraint values match the user input. The scanning resumes and the results are deduced. The final results are reported to the user. The process continues until the final selection. Fig 6 shows 
function editor and its session. Fig 7 shows the rules editor. Rule editor is used to define, examine and modify the rules.

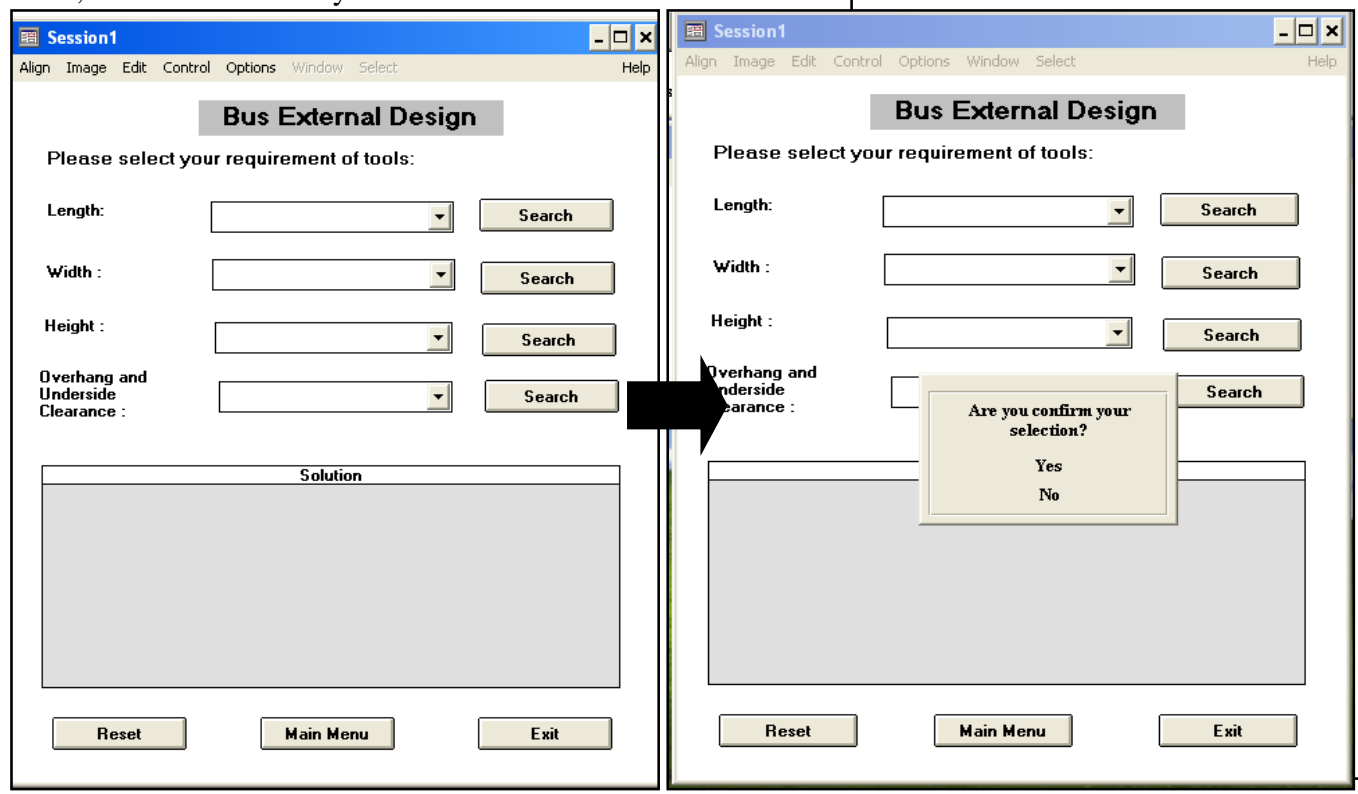

Fig. 4: Main layout session for user

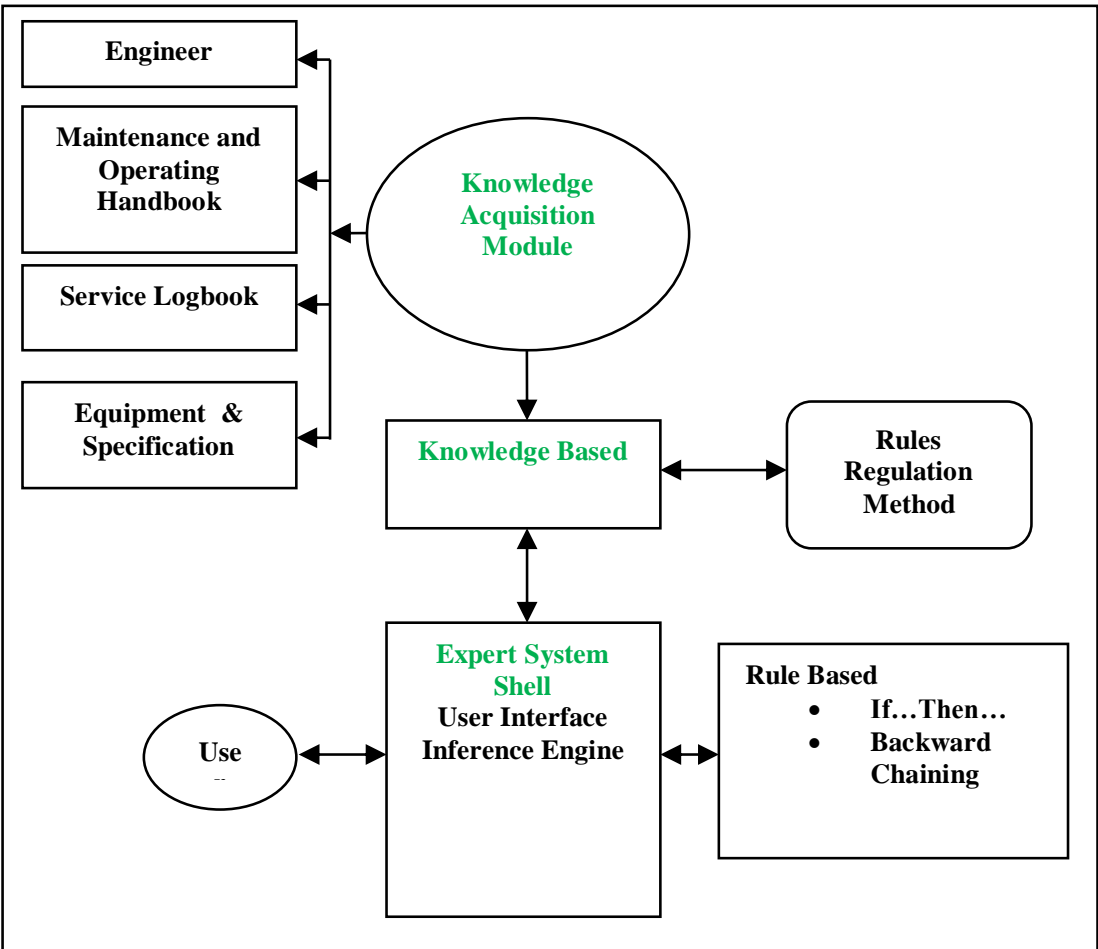

Fig. 5: The proposed framework for the expert system 


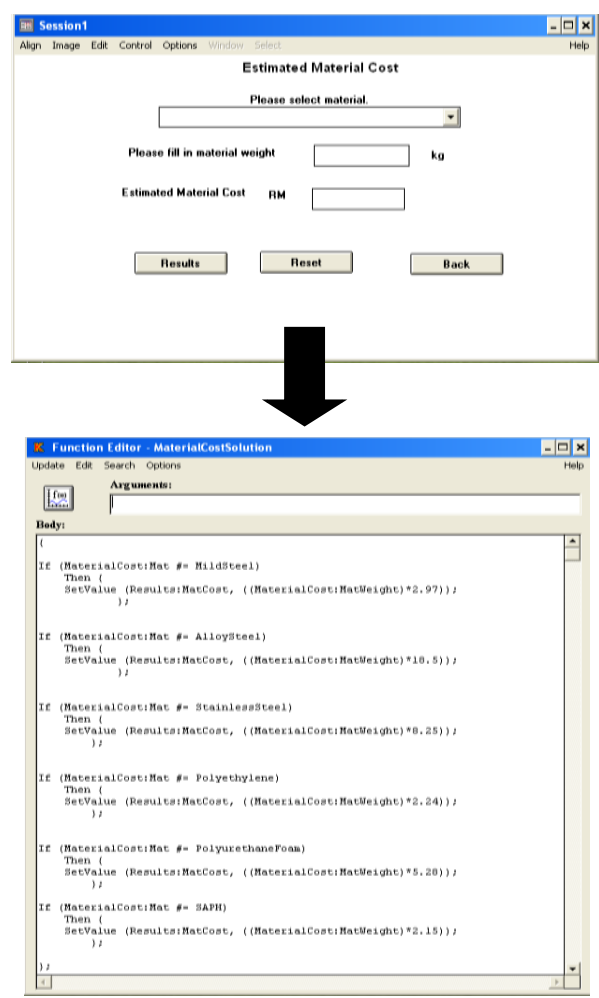

Fig. 6: Function editor and it's session

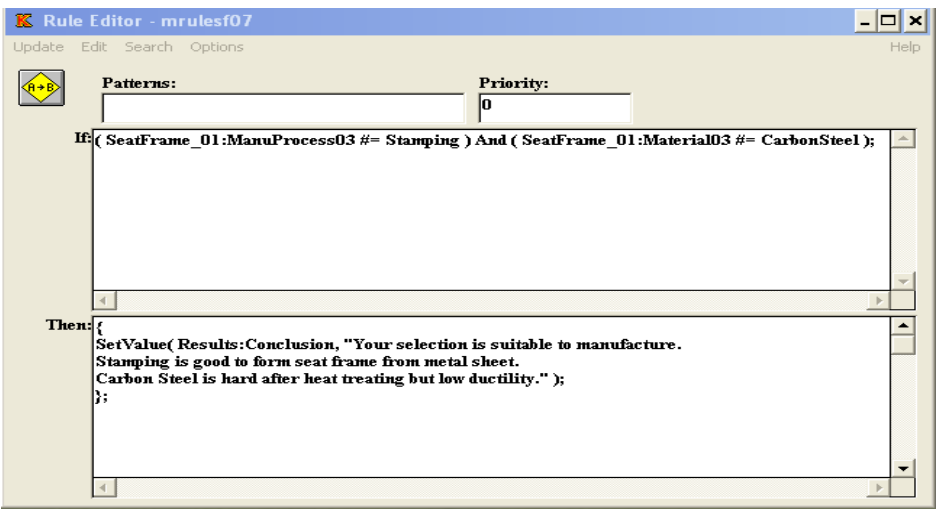

Fig. 7: The rule editor

\section{Case Study}

A case study has been conducted at the manufacture office plant where the specification and information regarding on the bus standard is given and validated by the engineers. All of the parameters and specifications are standardized and can be found at the Operational Maintenance and Service Manual. An Expert Fault
Diagnosis System framework for Commercial Bus involves a number of major steps. This includes knowledge acquisition, choosing the selection criteria, selection of user interface, define the knowledge hierarchy, program codes writing, program testing and validating. The developed framework helps the automotive engineers to shorten up the diagnosis time and increase the efficiency of the production line. Figures below show the technical drawing layout of the commercial bus. 


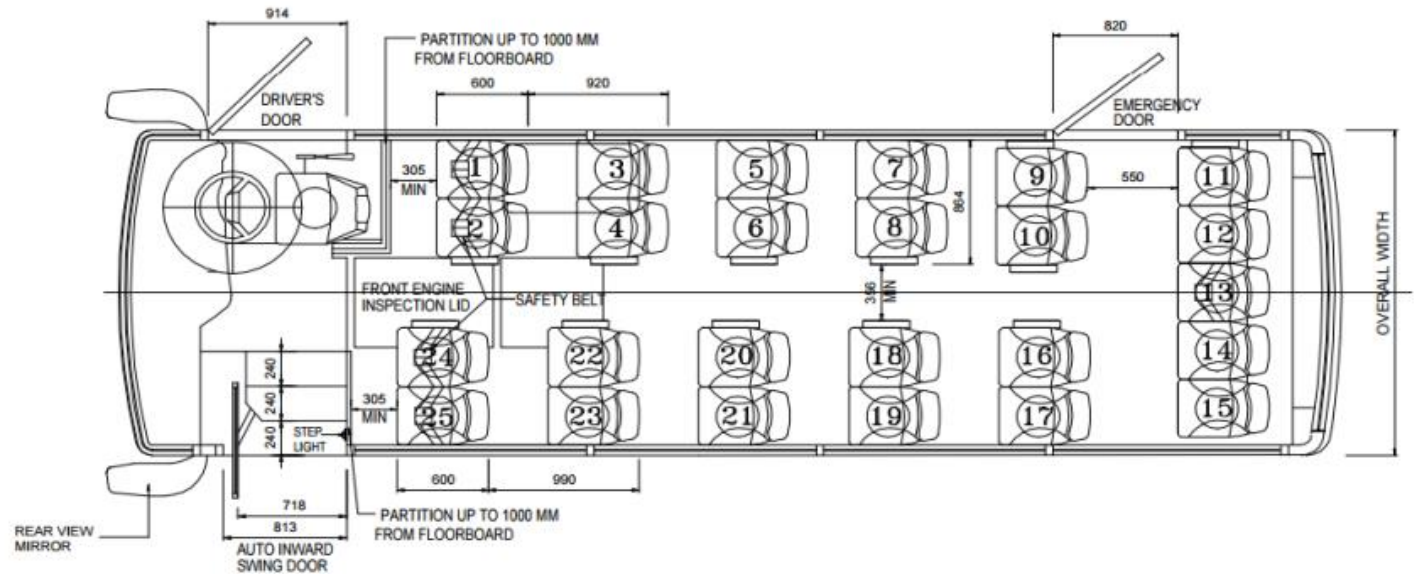

Fig. 8: The top view of the commercial bus design

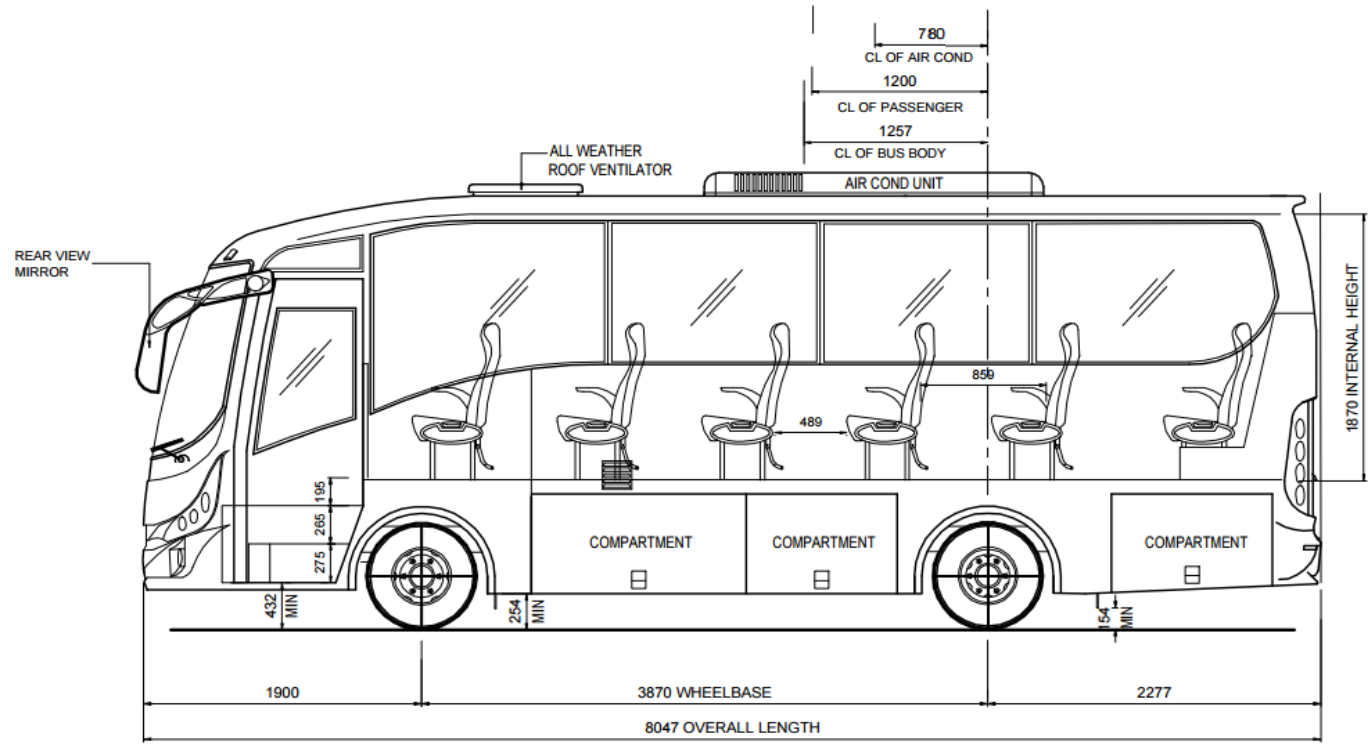

Fig. 9: The side view of the commercial bus design

Fig 10 shows four important stages which is the literature review and analysis, knowledge acquisition, development of framework and testing and validation. Literature review and analysis does contain the study on the elements, the functionalities, the core components and system architecture of the system. The analysis will give solutions to the problem and provide the best recoomendation that is needed to solve the issues. Phase 2 is the knowledge acquisition collects knowledge on the problem, which will be guiding the way of the software development. Knowledge acquisition is also the process of collecting knowledge from the expert and it involves meetings with the expert [18].
In the third phase, the existing fault diagnosis framework that has been developed is studied. All the knowledge including the geometrical and assembly parameters gained will be placed in development of the proposed framework. In addition, different types of techniques and prominent ideas are studied and emerged in order to construct the proposed fault diagnosis framework for commercial bus. In the last phase, researcher will liaise with the vehicle manufacturer for further testing and validation purposes. Fig 10 shows the overall operational process of the research. 


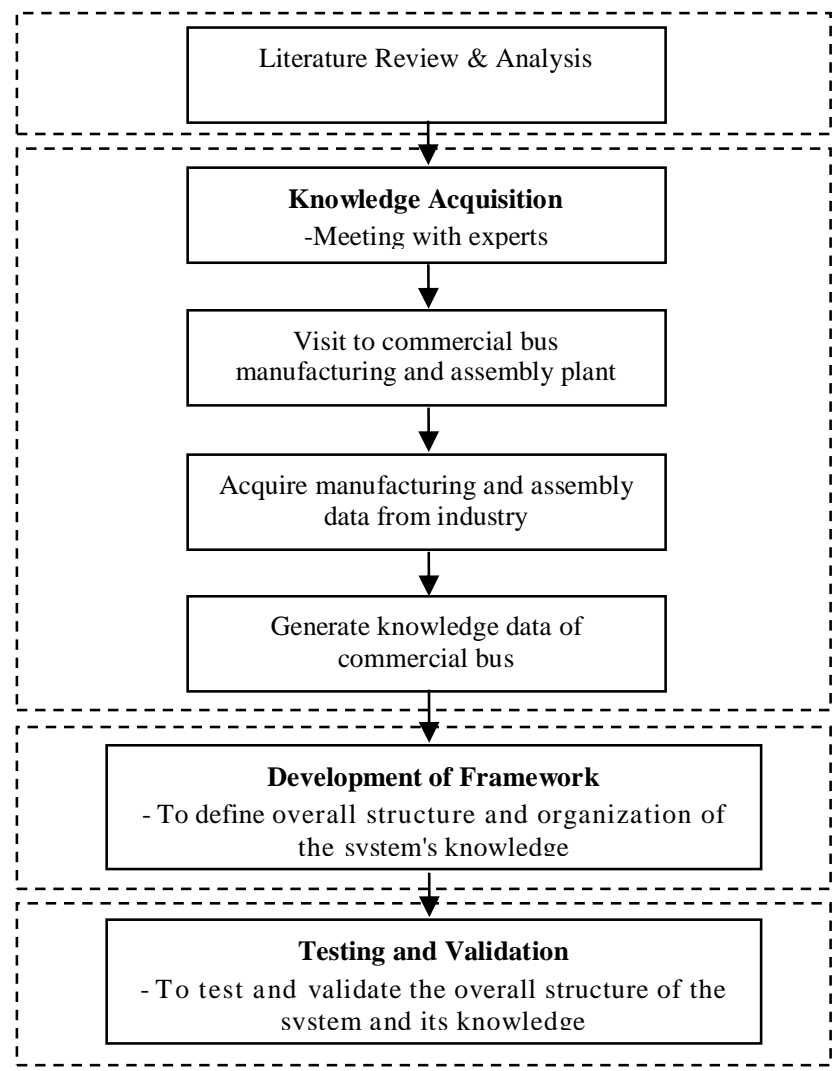

Phase 1

Phase 2

Phase 3

Fig. 10: The operational flow of research process

\subsection{Field Testing}

The developed system is deployed and validated with the real world problem. Table 2 shows the case study result. The developed expert system has the ability to diagnose the root problem to different type of situation and gives a precise recommendation.

A few technicians were asked to use the expert system to trouble shoot the bus design parameters. The main objective of the expert system is to determine whether the expert system meets the actual requirement.

Table 2: Case Study Result

\begin{tabular}{|c|c|c|c|c|}
\hline No & $\begin{array}{l}\text { Acceptable } \\
\text { Parameters }\end{array}$ & $\begin{array}{c}\text { User's } \\
\text { Parameters }\end{array}$ & Expert System Results & Match \\
\hline 1 & $\begin{array}{l}\text { Length } \\
\text { (From } 8 \mathrm{~m} \text { to } \\
12.5 \mathrm{~m} \text { ) }\end{array}$ & $25 \mathrm{~m}$ & $\begin{array}{l}\text { Failed. Standard bus } \\
\text { design varies from length } \\
8 \mathrm{~m} \text { to } 12.5 \mathrm{~m} .\end{array}$ & YES \\
\hline 2 & $\begin{array}{l}\text { Width } \\
\text { (From } 3 \mathrm{~m} \text { to } \\
4.3 \mathrm{~m} \text { ) }\end{array}$ & 3.0 & $\begin{array}{l}\text { Design width of } 3.1 \mathrm{~m} \\
\text { should be used and this } \\
\text { includes the } 230 \mathrm{~mm} \\
\text { extrusion of rear view } \\
\text { mirrors on both sides. }\end{array}$ & YES \\
\hline 3 & $\begin{array}{l}\text { Height } \\
\text { (From } 3 \mathrm{~m} \text { to } \\
3.3 \mathrm{~m} \text { ) }\end{array}$ & $5 \mathrm{~m}$ & $\begin{array}{l}\text { Failed. Ideal design } \\
\text { height is } 3.2 \mathrm{~m} .\end{array}$ & YES \\
\hline 4 & $\begin{array}{l}\text { Underside } \\
\text { clearance } \\
(75 \mathrm{~mm})\end{array}$ & $100 \mathrm{~mm}$ & $\begin{array}{l}\text { Failed. Underside } \\
\text { clearance at the axles is } \\
75 \mathrm{~mm} \text {. }\end{array}$ & YES \\
\hline
\end{tabular}

\section{Conclusion}

This developed system can helps design engineer with insufficient knowledge and experience in bus manufacturing industry by providing them with knowledge related on manufacturing process, material and method to manufacture the bus in an effective and lowcost way. The system can provide useful suggestion and recommendation on the material used to manufacture different parts of bus based on the knowledge and experience of expert.

Besides, this expert system can reduce the time of design stage. With the existence of this expert system, the designing problem can be solved in a shorter time when the expertise is not available. This system may provide an alternative way to help in reducing the man hours cost of a company by reducing the numbers of expert engineers. With the implementation of this expert system, company can preserves the priceless knowledge and experience to avoid the loss of expertise after the expert engineer is no longer available.

\section{Acknowledgements}

The authors are gratefully acknowledges the contributions from the member of the Innovation and Sustainability in Machine Technologies (i-SMAT) research group and UTeM Development Office. This research is supported by Research Acculturation Collaboration Effort (RACE) grant scheme, Ministry of Higher Education Malaysia (Grant Number RACE/F3/TK13/FKM/F00302). In addition, the authors do appreciate help from the Malaysia Road of Safety Department. 


\section{References}

[1] Roland Berger., 2016. Digitalization in the construction industry. Available at

<https://www.rolandberger.com/.../tab_digitization_construction_indu stry_e_final.pdf $>$ [Accessed on 27 November 2017]

[2] Gemignani, M., C, Lakshmivarahan., S. \& Wasserman. 1983. A.I, "ADVANCES IN COMPUTERS".

[3] Dym C. 1985. Expert systems: New approaches to computer aided engineering. J Eng Computer 1(3): 9-25.

[4] Terry Anthony Byrd. 1995. Expert systems implementation: interviews with knowledge engineers. Industrial Management \& data systems 95(10): 3-7.

[5] Xian, G and Zeng, B. 2009. An intelligent fault diagnosis method based on wavelet packer analysis and hybrid support vector machines. Expert Systems with Applications 36(10): 12131- 12136.

[6] Deng, S., Lin, S., and Chang, W. 2011. Application of multiclass support vector machines for fault diagnosis of field air defence gun. Expert Systems with Applications 38(5): 6007- 6013.

[7] Syiam, M. M. 2010. A neural network expert system for diagnosing eye diseases. Conference of the $10^{\text {th }}$ International Conference on AI for Applications, San Antonia, Texas, pp. 491-492.

[8] Wang, H. and Chen, Y., 2016. A robust fault detection and diagnosis strategy for multiple faults of VAV air handling units. Energy and Buildings, 127, pp. 442-451.

[9] P. Jackson. 1998. Introduction to Expert System. Addison Wesley.
[10] Catal, C., Sevim, U., and Diri, B. 2011. Practical development of an Eclipse-based software fault prediction using Naïve Bayes algorithm. Expert Systems with Applications, 38(3), 2347-2353.

[11] Lei, Y., He, Z., and Zi, Y. 2011. EEMD method and WNN for fault diagnosis of locomotive roller bearing. Expert Systems with Applications 38(6): 7334- 7341.

[12] Liebowitz, J. 1995. Implications for a Generic Expert Scheduling System Architecture and Toolkit. Expert Systems with Applications, 9(3): 423-432 .

[13] Rupnawar, A., Jagdale, A. and Navsupe, S., 2016. Study on Forward Chaining and Reverse Chaining in Expert System. International Journal of Advanced Engineering Research and Science, 3(12), pp. 60-62.

[14] IntelliCorp. 2006. Kappa-PC User's Guide. (Version 2.0, IntelliCorp, Inc., USA.)

[15] Fiannaca, A., Rosa, M. L., Rizzo, R., Urso, A., and Gaglio, S., 2014. An expert system hybrid architecture to support experiment management. Expert Systems with Applications, 41(4), pp. 1609-1621.

[16] Mansyur. R., Rahmat. R.A.O.K., \& Ismail, A. 2013. A Prototype Rule-Based Expert System for Travel Demand Management. UNIMAS E-Journal of Civil Engineering 4 (4): 34-39.

[17] C. K,, \& Ercelebi. S. G. 2009 .An Expert System for Hydraulic Excavator and Truck Selection in Surface Mining. The Journal of the Southern Africian Institute of Mining and Metallurgy 109: 727-738.

[18] Al-Ajlan, A., 2015. The Comparison between Forward and Backward Chaining. International Journal of Machine Learning and Computing, 5(2), pp. 106-113. 